\title{
Concept Clarification of Moral Case Deliberation
}

\author{
Dara Rasoal \\ School of Health, Care and Social Welfare, Malardalen University, Vasteras, Sweden \\ Email: dara.rasoal@mdh.se
}

How to cite this paper: Rasoal, D. (2018) Concept Clarification of Moral Case Deliberation. Open Journal of Nursing, 8, 390-403.

https://doi.org/10.4236/ojn.2018.86031

Received: May 14, 2018

Accepted: June 25, 2018

Published: June 28, 2018

Copyright $\odot 2018$ by authors and Scientific Research Publishing Inc. This work is licensed under the Creative Commons Attribution International License (CC BY 4.0).

http://creativecommons.org/licenses/by/4.0/

\begin{abstract}
Background: Health care professionals have encountered ethically difficult situations for decades in their clinical practice. Various clinical ethics support has been established in order to deal with these issues. Moral case deliberation is a new developed approach that deliberates over ethically difficult cases in clinical practice. However, there is lack of knowledge that describes the characteristics of the moral case deliberation and how this differs to related clinical ethics support where a concept analysis may clarify the differences. Aim: To analyse the concept of moral case deliberation and related concepts. Methods: Integrative literature review. Rodger's evolutionary view of concept analysis has been used for clarification of the concept. Using specific keywords in the databases, searching for peer-reviewed academic paper published in English between 1995-2017 in the CINAHL, MEDLINE, Psych Info, Academic Search Elite and AMED. Results: Moral case deliberation (MCD) was defined as an approach with four specific characteristics: 1) Perspective sharing via dialogue, 2) training moral awareness, 3) moral emotional deliberation, and 4) moral support and joint learning. The presence of a facilitator who is trained in a specific method for the MCD reflection seemed to be important when stimulating the discussion from a patient perspective. Conclusions: Clarify the concept of moral case deliberation can be useful for healthcare professionals when choosing a facilitate-base reflection. Through a mutual dialogue and perspective sharing can MCD train staff members in moral awareness, create a space for emotions to be expressed and finally work as an platform for joint learning.
\end{abstract}

\section{Keywords}

Moral Case Deliberation, Staff, Ethics, Healthcare, Nursing, Concept Analysis

\section{Introduction}

Progress in technology and medical advancement in the twentieth century in 
parallel with improvements in living conditions and persons' changing lifestyles have been successful regarding aging in developed societies [1] [2]. These developments also mean that many people are living longer with problems associated with chronic disease. Healthcare has developed and advanced treatments and methods in order to treat diseases and maintain life. Providing a treatment could mean that a patient's individual autonomy is sometimes ignored [3]. The staff who care for such people may have opinions on how the treatment or care should be provided. Furthermore, the family members may also have opinions on care and treatment. There have been major ethical challenges for staff to provide person-centred care, both in the hospital setting and in the municipality. Nurses today face ethical challenges in providing person-centred care in clinical practice. Nurses are facing ethical issues and moral dilemmas are common [4].

To provide good and person-centred care requires not only medical skills, knowledge transfer and communication, but also ethical awareness and self-reflection [5]. Health care professionals have been confronted with ethically difficult situations for decades [6] [7] and various types of clinical ethics support [8] [9] have developed through research. Moral Case Deliberation (MCD) is a recently developed concept which has been defined in previous scientific articles. The concept has been defined as completely distinct to ethical consultation, an older and more common method of resolving ethical dilemmas in healthcare. Clarification of the concept of MCD is necessary, as it is becoming more widely used in European healthcare settings. Therefore it is essential to provide a concept clarification of moral case deliberation.

Ethical issues have been a major challenge for health care institutions for addressing the needs of patient care in an ethically acceptable manner [10] [11]. Nurses are predominantly the largest group to be confronted with these issues [12]. Since the first report, nearly 40 years ago ethical issues have been deliberated [13], and various clinical ethics support; ethics committees, ethics consultation and moral case deliberation (Libow et al. 1992; Molewijk et al. 2008a; Altisent et al. 2013) have been established in order to help health care professionals dealing with these issues.

Over the last decade a new concept developed in order to support staff dealing with moral issues, namely moral case deliberation (MCD) [14]. MCD is a growing concept of case deliberation in many European countries, predominantly in the Netherlands. The concept needed to be clarified in order to increase understanding differences in relation to other clinical ethics support.

\section{Methods}

The process of concept analysis was performed using the steps outlined in Rodgers' [15] evolutionary method. In this a clarification of the concept will be provided from a linguistic level as to what "moral", "case" and "deliberation" each mean along with a discussion of their relevance to ethics (Table 1).

The first step was to identify the interdisciplinary fields of sources appropriate 
Table 1. Rodgers' Evolutionary Method for Concept Analysis (Rodgers, 1989).

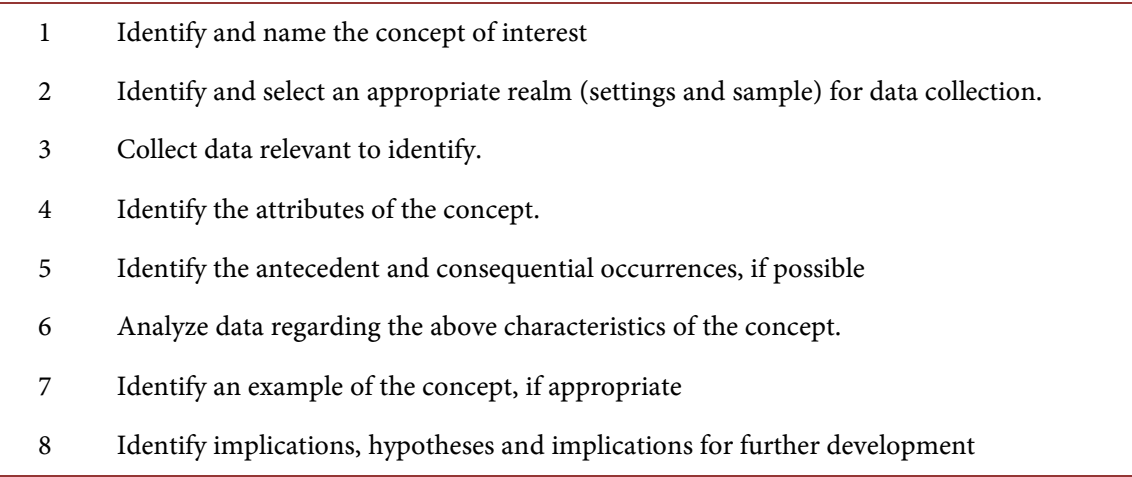

for data collection. Then, the attributes of the concept, as well as surrogate and related concepts, and antecedents and consequences were described. Finally, implications for further development were generated.

The literature search was systematically conducted together with a professional librarian from the university. Firstly, together with the librarian, a search was conducted to identify relevant keywords that were specific and relevant to the concept. The search for this concept was conducted systematically in the databases CINAHL, Medline, Psych Info, Academic Search Elite and AMED. A search history was created within the database where the author and the librarian discussed how to combine various search keywords responded to the purpose of the concept. Search terms used were: ethical deliberation, moral deliberation, case deliberation, moral case deliberation, ethical case deliberation, ethics round, clinical ethics round, ethical discussion, health care professionals, nurse, nursing, caring. The search generated 55 responses in Cinahl, 110 in Medline, 103 in Psychinfo, Academic search elite, and 3 in Amed. In total 427 articles, books, dissertations and policy documents were found. See the search strategy in Figure 1.

Included articles were from 1995 to 2017 and were limited to English language, full text and peer-reviewed literature. We excluded literature which contained unpublished dissertations, policy documents, book reviews and articles with no relevance. Articles which did not have a focus on ethics deliberation or related surrogate terms were also excluded. In order to avoid bias, the literature search was not restricted to nursing literature. In order to help define the concept an online dictionary and philosophical works were also included in the search. The data were also searched in philosophical work and online dictionary in order to define the concept. The next step in the searching was to combine different search terms according to the following (Figure 1).

Data analysis: A wide range of articles were found during the search, including teaching ethics, ethics rounds, ethical deliberation, and moral deliberation. In total 24 theoretical and empirical studies were selected which concerned moral case deliberation. In the first step the key characteristics of the concept were found. From this, in a second step, defining and analyzing attributes of the concept 


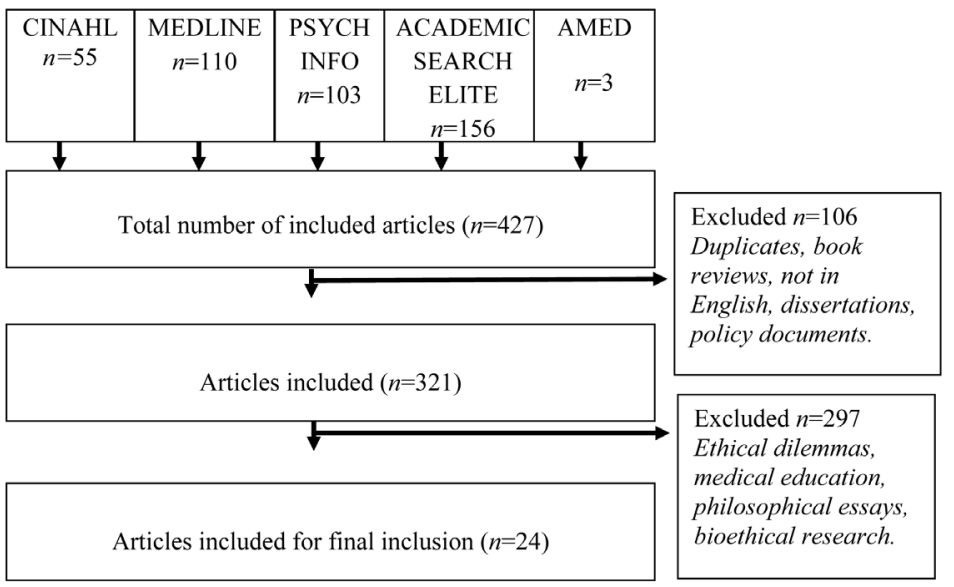

Figure 1. Search strategy. Search terms and combinations used in the databases Cinahl, Medline, Psych INFO, Academic Search Elite and Amed: \#1 ethical deliberation; \#2 moral deliberation; \#3 case deliberation; \#4 moral case deliberation; \#5 ethical case deliberation; \#6 ethics round; \#7 clinical ethics; \#8 ethical discussion; \#9 health professionals; \#10 nurse; \#11 nursing; \#12 caring. Combinations: (\#1 OR \#2 OR \#3 OR \#4 OR \#5 OR \#6 OR \#7 OR \#8) AND (\#9 OR \#10 OR \#11 OR \#12).

were generated, in part through comparison with related concepts. In a third stage, the concept is further exemplified through discussion of examples or cases that are exemplary, related or contrary [16]. In a fourth and final stage, the antecedents and consequences of the use of the concept are described (Table 2).

\section{Results}

1) Development of the concept Moral Case Deliberation (MCD)

The earliest uses of the term moral deliberations concerned the analogy of the methodological and theoretical comparison between decision-making theory which was named the "decisionist" approach, and the "deliberationist" approach [17]. The idea of case deliberation for health care professionals was further developed by philosophers Steinkamp and Gordijn (2003). They described a theoretical background of ethical case deliberation in comparison with four other existing methods from a philosophical perspective. The concept Moral deliberation developed when it was used for the first time a model for care in psychiatric nursing practice [18]. The concept was extended by including the concept of "CASE", when it became known as Moral Case Deliberation, having been first defined by the Dutch ethicist Bert Molewijk (2008). MCD concerned its implementation in a range of Dutch healthcare settings [19].

The concept MCD has been defined in several ways: it consists of a collaborative, systematic reflection on a real clinical case [20], methodological reflection on concrete moral cases among health care professionals [19], a facilitator-led collective moral inquiry of healthcare professionals into a concrete moral question connected to a real case in their practice [21]. These definitions highlight the presence of a facilitator, a concrete ethical problem, and the use of collective reflection. Some researcher mentioned that the facilitator is specially trained 
Table 2. The outline of antecedents, attributes and consequences of the concept moral case deliberation.

\begin{tabular}{|c|c|c|}
\hline Antecedents & Attributes & Consequences \\
\hline $\begin{array}{l}\text {-Morally difficult situations } \\
\text {-Moral conflict } \\
\text {-Moral dilemmas } \\
\text {-Moral issues }\end{array}$ & $\begin{array}{l}\text {-Perspective sharing via } \\
\text { dialogue. } \\
\text {-Training moral } \\
\text { awareness. } \\
\text {-Moral emotional } \\
\text { deliberation. } \\
\text {-Moral support and joint } \\
\text { learning. }\end{array}$ & $\begin{array}{l}\text {-Improved communication among } \\
\text { healthcare staff. } \\
\text {-Better ability to recognize moral } \\
\text { dilemmas. } \\
\text {-Greater moral awareness. } \\
\text {-Improved quality of patient care } \\
\text {-Consider institutional and } \\
\text { organizational change in order to } \\
\text { improve quality of care. } \\
\text {-Staff are able to make independent and } \\
\text { competent decision. } \\
\text {-Improved morale (confidence) }\end{array}$ \\
\hline
\end{tabular}

[22]; others that they have a background in ethics [23]. Often, but not always, a specific conversation method is applied, such as the Dilemma method [14] in which a consensus is sought [19] or the Socratic Dialogue, which aims to help professionals develop moral skills and an appropriate, reflective attitude [20]. In other words, MCD can serve as a way to deal with concrete problems and to train moral competencies at the same time. From this starting-point, it is clear that while the concept embraces a range of aspects, there are commonalities.

2) Defining attributes

In order to clarify the meaning of the concept, we have examined dictionary definitions. The term "Moral Case Deliberation" is a recent development, and therefore was not present in the standard dictionaries or indexed in the databases CINAHL, Pub Med and Medline. Therefore, since it is a three-word concept, the words "moral", "case" and "deliberation" were examined separately in the Oxford English Dictionary.

Concerning moral: There is a wide range of definitions, the most appropriate definition of moral for this study purposes was: Treating of or concerned with the nature of good and evil, right and wrong, or the rules of right conduct, as a subject of study [24] [25].

Concerning case: The most suitable definition for this paper was: An instance of a particular situation; an example of something occurring [24] [25].

Concerning deliberation: The appropriate definition was: The action of deliberating, or weighing a thing in the mind; careful consideration with a view to decision, or careful slowness [24] [25].

Having examined the words that make up the concept, as well as descriptions in the academic literature, a range of aspects of moral case deliberation has emerged. This section will define the concept in terms of its necessary and sufficient characteristics. The MCD characterized as collective reflection over an authentic case with ethical or moral nature where the dialogue is facilitated by an ethicist whose function is to create a discussion using a specific method (Socratic dialogue or Dilemma method). The following attributes, are present in moral 
case deliberation: 1) Perspective sharing via dialogue, 2) training moral awareness, 3) moral emotional deliberation, 4) moral support and joint learning. These attributes are displayed in Table 3.

3) Perspective sharing via dialogue

In healthcare settings moral issues are often deliberated through moral dialogue among staff members, patients and other stakeholders [20]. These moral deliberation dialogues are distinct from other types of dialogue since they focus on human values and experiences rather than other things, for example, technical objects. Moral dialogues are intended to create the right conditions for mutual understanding and they function as a means for staff to provide good care [26]. One of the crucial roles of the dialogue is that it can function as a model for sharing perspectives and deliberating over moral issues in healthcare [26] [27] [28] by letting the staff tell their narratives [29] where through dialogue they develop a new way of seeing and acting with the experience they have but in a different manner [28]. In this dialogue the professionals are asked to be involved in an argumentation where they could explain moral quandaries [8]. Other aspects of the moral dialogue concerns the outcome in which provide learning [30]

4) Training moral awareness (individual and group)

The MCD facilitators with their knowledge in ethics support staff members ability in joint reasoning, and foster a systematic and constructive dialogue from a moral perspective [14]. Moral awareness and competencies are enhanced as the result of moral reflection by being distant from the practice, and seeing it from another perspective [31]. They are also enhanced through learning to reflect ethically by the fact of doing it in a practical way [32]. The starting point for moral awareness when the staff gather to discuss and reflect on ethical issues in a group, and ask questions concerning right and wrong [20] [33].

5) Moral emotional deliberation

Table 3. Overview over advantages and disadvantages using concept analysis.

\begin{tabular}{|c|c|}
\hline Advantages & Disadvantages \\
\hline $\begin{array}{l}\text { To operationalize a concept used in clinical } \\
\text { practice }\end{array}$ & $\begin{array}{l}\text { Concept analysis cannot generate a new concept } \\
\text { but only validate the existing concepts reflected } \\
\text { on a theoretical base. }\end{array}$ \\
\hline $\begin{array}{l}\text { To perform research using logical, systematic } \\
\text { and intellectual analysis when clarifying } \\
\text { meaning }\end{array}$ & $\begin{array}{l}\text { It is a rigorous process that requires long time in } \\
\text { reading and rereading, including persistent focus } \\
\text { on the concepts of interest. }\end{array}$ \\
\hline To develop measuring instruments & $\begin{array}{l}\text { There are no firm rules on how to go about the } \\
\text { process when doing concept analysis, therefore } \\
\text { an individual may be unsure of how to start the } \\
\text { process. }\end{array}$ \\
\hline To refine and validate & $\begin{array}{l}\text { The researcher can feel overwhelmed and } \\
\text { uncertain how to deal with a large volume of } \\
\text { data }\end{array}$ \\
\hline $\begin{array}{l}\text { To clarify ambiguous concepts that is used as } \\
\text { synonymous }\end{array}$ & $\begin{array}{l}\text { Analyzing a concept may result in value } \\
\text { attachment. It may cloud the analytic processes } \\
\text { in the researcher and thus jeopardize the whole } \\
\text { research process }\end{array}$ \\
\hline
\end{tabular}


Healthcare staff are surrounded by ethically difficult situations in clinical practice [34], where emotions play a fundamental role in an informative way in describing moral inquiry [22] [35], moral judgment and decision-making [36]. In moral deliberation the staff process their thinking and feelings related to a patient case they interacted with (Molewijk et al. 2008c; Plantinga et al. 2012) and it was found that MCD could enhance emotional support [37]. There are both positive and negative emotions where positive emotions relate to feeling valuable, supportive, helping patients and relatives. It also gives a sense of doing something good for others and showing compassion [35]. Bad emotions related to ethically difficult situations could be frustration, uneasiness, powerlessness and uncertainties in staff-patient or next-of-kin relationship [34].

6) Moral support and joint learning

One of the attributes that pervades the concept of Moral Case Deliberation is to give moral support to the staff and increase the ability to learn from each other. The MCD discussion and moral support can enhance staff members' understanding of each other's' reasoning and acting [19] [38]. Moral support could be given by either the facilitator during the MCD or from the staff members to each other. This kind of support should be neutral in that the person who supports should be impartial in order to avoid conflict. In the MCD the facilitators is the person who supports the staff sometimes through training or experience in order to develop their facilitator abilities. For example, abilities for listening, patience, responsibility [23] [32]. Staff working in elderly care use ethics support in order to deliver good care, but because of other priorities less attention has been given to ethics support [39].

7) Identify antecedents and consequences

The identification of antecedents and consequences helps to refine the critical attributes and to map out the contexts in which the concept is generally used [15]. Antecedents describe important situations, events or incidents that must occur prior to the occurrence of the concept of interest. Antecedents help in understanding the concept in a particular social context [40]. In contrast, consequences occur as a result of the use of the concept. The consequences of moral case deliberation might be: Improve moral communication among healthcare staff, better ability to recognize moral dilemmas, greater moral awareness, improved quality of patient care, consider institutional change in order to improve quality of care, staff are able to make independent and competent decision and improved morale.

\section{8) Related concepts}

In the previous section, I provided definitions of the words "moral", "case", and "deliberation" from dictionaries and examined how the academic literature defines the whole concept. In the next step I suggested possible defining attributes of the concept. Now it is possible to examine two concepts, which are closely linked to MCD but which, in each case, have slightly different meanings.

A related concept has most but not all of the characteristics that define the concept of MCD. I am describing related concepts because I want to explain the 
differences and similarities between MCD and two related concepts: ethical consultations and ethics rounds [41].

9) Ethical consultation

Ethics consultation is a service provided by an expert in ethics to help healthcare professionals deal with ethical problems in healthcare. The purpose of ethical consultations is to improve the quality of healthcare for the patient. Ethics consultations have been shown to help patients and professionals clarify ethical problems arising in the daily practice of healthcare and to improve collaborative decision-making [42] [43]. Consultations can be carried out by individual consultants or by ethics committees, generally following requests by healthcare professionals or by patients or their surrogates [44] [45]. In ethics consultation staffs discuss the nature of ethical problems which they are facing in their everyday practice. Ethics consultation is led by consultants trained in ethics. The purpose of ethics consultations is to increase moral competencies and to resolve ethical problems between staff and patients thorough dialogue. Therefore, although this concept involves discussion of ethical aspects of a concrete case, the parties do not discuss the case collectively, but individually with the consultant. In addition, the ethics consultant has an influential advisory role and may propose solutions [46]. They are not merely a facilitator in the sense of MCD, where mutual dialogue occurs and everybody is equal. Therefore, the related case of ethics consultation does not fit all of the defining attributes of MCD.

10) Ethics round

Ethics rounds concern medical and moral problems where healthcare professionals from different disciplines come together to discuss a patient case which they find ethically difficult to resolve. The purpose of ethics rounds is to help healthcare professionals reflect and discuss healthcare issues, specifically ethical aspects [47]. Ethics rounds from a healthcare perspective describe a patient's medical issues and ethical issues which are connected to the case through a conversation led by a facilitator. The goal of the ethics round is through discussion, particularly through listening to each other's perspectives, to improve patient care and illuminate medical practice in everyday work [48]. Ethics rounds aim also to improve ethical competencies and help healthcare professionals to deal with ethical dilemmas [47] or provide training in moral reasoning through reflections upon ethical decision-making [38]. The case of ethics rounds fulfils all five defining attributes. It is difficult to distinguish ethics rounds from MCD, in part because of the breadth of the concepts, which overlap greatly (Table 4).

\section{Discussion and Conclusion}

This article has defined the four attributes of $\mathrm{MCD}$, and can provide a definition, which corresponds to its use in the literature. It was possible to distinguish MCD from ethical consultation, but not from the term ethical rounds. Attempts to review the defining attributes of MCD in order to exclude ethical rounds were unsuccessful. This is perhaps because the terms can be used interchangeably, in 
Table 4. The effects of Moral Case Deliberation for healthcare staff.

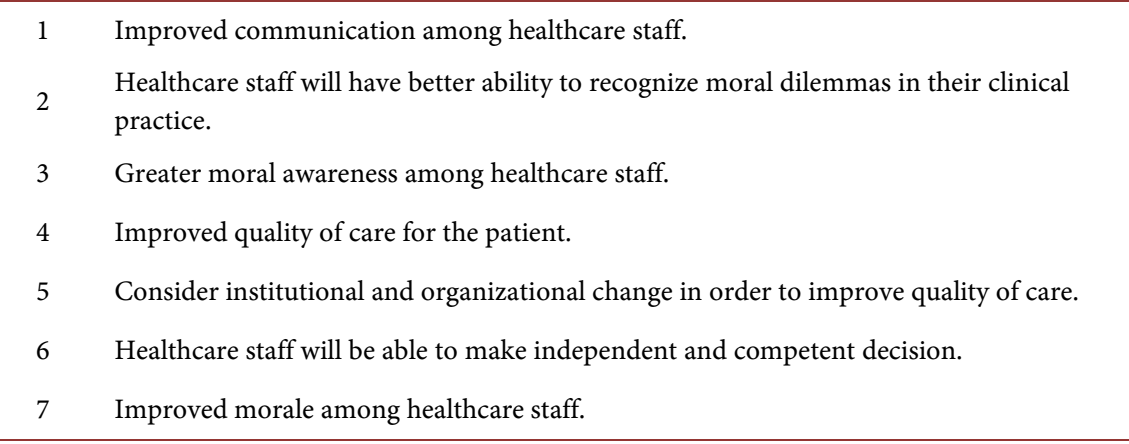

one study the MCD described as an umbrella term for ethics rounds [37], alongside other terms such as ethical case discussion and ethics reflection groups which are also used in the healthcare setting. However, it was clear that a contrary case, involving a hierarchical discussion between a doctor and a nurse, did not fulfill any of the criteria of MCD. This concept of moral case deliberation has been analyzed using Rodger's method of concept analysis. The clarification of the moral case deliberation was necessary for the ongoing ethical reflection for healthcare personnel. It is important to understand the distinction and characteristics of moral case deliberation in relation to other related approaches. The distinction emphasizes that in moral case deliberation there are certain aspects that must be considered when providing ethical support. Moral case deliberation emphasizes that the ethical reflection needs to be facilitated by an external facilitator with knowledge of ethics [32]. The role of the facilitator is also to keep an eye on the group's emotions related to the ethically difficult situation that they experience [35]. Ethically difficult situations are a large part of the day-to-day increasing challenges for staff working in healthcare settings and it involves various contexts and situations [49] [50] [51] [52]. These issues have often been deliberated in a group discussion among nurses and other health care staffs. They include circumstances in which moral obligations demand or appear to demand that staff adopt each of two alternatives but incompatible actions, but cannot perform any of these alternatives [3]. The bioethics literature has clarified ethical issues in terms of conflict and choice among values, beliefs and options for action. Others, in contrast, find that ethical issues are more about the relationship and attitudes in profession [53]. The discussion and variety of views about what makes a problem to ethical problem indicate that the moral domain is probably wider and richer than mainstream bioethics generally describe.

Our clarification of the concept might be limited by the fact that the search of databases only spanned a twelve-year period from 1995-2017. The results indicate that there are more similarities than differences between different kind of clinical ethics support such as ethics rounds and ethics consultation in relation to MCD. However, this is not surprising since all these methods focus on how to deal with ethically difficult situation rather than what is right action to do in an ethically difficult situation. 
Identifying the antecedents and attributes embedded in the concepts may raise staff awareness of the different clinical ethics support and how they are constructed.The consultant within the clinical ethic support can choose an approach with a "top-down" perspective. This perspective can be understood as an authoritarian approach where he/she can decide the best course of action in a particular ethically difficult situation. The consultant/facilitator can also have a mutual "Bottom-up" manner in the interaction with staff, which seems to be the case in MCD. With a "Bottom up" perspective, the personnel can bring a case from their clinical practice, reflect together with the facilitator in an interaction and reach a consensus about what to do.

Another aspect that is important to consider in moral case deliberation is the value of emotions. In the MCD the staffs are allowed to express their emotions which are related to the ethically difficult situation they experience and which did not seem to be clear in the ethics round and ethics consultation. Emotions have been described as important and informative in a relationship between staff [35] [54].

Consequences of the MCD seemed to be: improving communication among healthcare staff, the staff will be able to recognize ethically difficult situations; they could develop greater moral awareness and improved quality of patient care. They would also consider institutional and organizational change in order to improve quality of care, and finally the staff would be able to make independent and competent decision and improved morale (confidence).

\section{Conflict of Interest}

The author declares that there is no conflict of interest.

\section{Funding}

This research received no specific grant from any funding agency in the public, commercial, or not-for-profit sectors.

\section{References}

[1] Callahan, D. (1995) What Kind of Life: The Limits of Medical Progress. George Town University Press, Washington DC.

[2] Parker, M.G. and Thorslund, M. (2007) Health Trends in the Elderly Population: Getting Better and Getting Worse. The Gerontologist, 47, 150-158. https://doi.org/10.1093/geront/47.2.150

[3] Beauchamp, T.L. and Childress, J.F. (2009) Principles of Biomedical Ethics. 7th Edition, Oxford University Press, Oxford.

[4] Ulrich, C.M., Taylor, C., Soeken, K., O’Donnell, P., Farrar, A., Danis, M., et al. (2010) Everyday Ethics: Ethical Issues and Stress in Nursing Practice. Journal of Advanced Nursing, 66, 2510-2519.

https://doi.org/10.1111/j.1365-2648.2010.05425.x

[5] McCormack, B. and McCance, T.V. (2006) Development of a Framework for Person-Centred Nursing. Journal of Advanced Nursing, 56, 472-479. https://doi.org/10.1111/j.1365-2648.2006.04042.x 
[6] Levine, M.D., Scott, L. and Curran, W.J. (1977) Ethics Rounds in a Children's Medical Center: Evaluation of a Hospital-Based Program for Continuing Education in Medical Ethics. Pediatrics, 60, 202-208.

[7] Smith, J.P. (1980) The Ethics of Resource Allocation in Health Care. Journal of Advanced Nursing, 5, 559-560. https://doi.org/10.1111/j.1365-2648.1980.tb03186.x

[8] Verkerk, M., Lindemann, H., Maeckelberghe, E., Feenstra, E., Hartoungh, R. and de Bree, M. (2004) Enhancing Reflection: An Interpersonal Exercise in Ethics Education. Hastings Center Report, 34, 31-38. https://doi.org/10.2307/3528175

[9] Bruce, C.R., Smith, M.L., Hizlan, S. and Sharp, R.R. (2011) A Systematic Review of Activities at a High-Volume Ethics Consultation Service. The Journal of Clinical Ethics, 22, 151.

[10] Beauchamp, T.L. (2003) Methods and Principles in Biomedical Ethics. Journal of Medical Ethics, 29, 269-274. https://doi.org/10.1136/jme.29.5.269

[11] Butts, J.B. and Rich, K. (2008) Nursing Ethics: Across the Curriculum and Into Practice. 2nd Edition, Jones \& Bartlett Publishers, Ontario.

[12] De Casterlé, B.D., Izumi, S., Godfrey, N.S. and Denhaerynck, K. (2008) Nurses' Responses to Ethical Dilemmas in Nursing Practice: Meta-Analysis. Journal of Advanced Nursing, 63, 540-549. https://doi.org/10.1111/j.1365-2648.2008.04702.x

[13] Spike, J. and Greenlaw, J. (2000) Ethics Consultation: High Ideals or Unrealistic Expectations? Annals of Internal Medicine, 133, 55-57. https://doi.org/10.7326/0003-4819-133-1-200007040-00010

[14] Molewijk, A.C.B., Abma, T.A., Stolper, M. and Widdershoven, G.A.M. (2008) Teaching Ethics in the Clinic. The Theory and Practice of Moral Case Deliberation. Journal of Medical Ethics, 34, 120-124. https://doi.org/10.1136/jme.2006.018580

[15] Rodgers, B.L. (1989) Concepts, Analysis and the Development of Nursing Knowledge: The Evolutionary Cycle. Journal of Advanced Nursing, 14, 330-335. https://doi.org/10.1111/j.1365-2648.1989.tb03420.x

[16] Tofthagen, R. and Fagerstrøm, L.M. (2010) Rodgers' Evolutionary Concept Analysis-A Valid Method for Developing Knowledge in Nursing Science. Scandinavian Journal of Caring Sciences, 24, 21-31. https://doi.org/10.1111/j.1471-6712.2010.00845.x

[17] Garcia, D. (2001) Moral Deliberation: The Role of Methodologies in Clinical Ethics. Medicine, Health Care and Philosophy, 4, 223-232. https://doi.org/10.1023/A:1011445128427

[18] Abma, T.A. and Widdershoven, G.A. (2006) Moral Deliberation in Psychiatric Nursing Practice. Nursing Ethics, 13, 546-557. https://doi.org/10.1191/0969733006nej892oa

[19] Molewijk, B., Verkerk, M., Milius, H. and Widdershoven, G. (2008) Implementing Moral Case Deliberation in a Psychiatric Hospital: Process and Outcome. Medicine, Health Care and Philosophy, 11, 43-56. https://doi.org/10.1007/s11019-007-9103-1

[20] Molewijk, B., Abma, T.A., Stolper, M. and Widdershoven, G. (2008) Teaching Ethics in the Clinic. The Theory and Practice of Moral Case Deliberation. Journal of Medical Ethics, 34, 120-124. https://doi.org/10.1136/jme.2006.018580

[21] Svantesson, M., Karlsson, J., Boitte, P., Schildman, J., Dauwerse, L., Widdershoven, G.A.M., et al. (2013) Moral Case Deliberation: Experienced Outcomes and Their Perceived Importance-The Development of an Evaluation Instrument (the Euro-MCD). 20.

[22] Weidema, F., Molewijk, B., Kamsteeg, F. and Widdershoven, G. (2013) Aims and 
Harvest of Moral Case Deliberation. Nursing Ethics, 20, 617-631. https://doi.org/10.1177/0969733012473773

[23] Plantinga, M., Molewijk, B., Bree, M., de Moraal, M., Verkerk, M. and Widdershoven, G. (2012) Training Healthcare Professionals as Moral Case Deliberation Facilitators: Evaluation of a Dutch Training Programme. Journal of Medical Ethics, 38, 630-635. https://doi.org/10.1136/medethics-2012-100546

[24] Pollard, E. and Liebeck, H. (1994) Oxford Dictionary-Ideal for Home and Office. Oxford University Press, New York.

[25] Lüpke, P., Grøn, A., Hartman, J. and Lüpke, P. (2004) Filosofi lexikonet. Almqvist \& Wiksell Tryckeri AB, Stockholm, Sweden.

[26] Abma, T.A., Molewijk, B. and Widdershoven, G. (2009) Good Care in Ongoing Dialogue. Improving the Quality of Care through Moral Deliberation and Responsive Evaluation. Health Care Analysis, 17, 217-235. https://doi.org/10.1007/s10728-008-0102-Z

[27] Ipperciel, D. (2003) Dialogue and Decision in a Moral Context. Nursing Philosophy, 4, 211-221. https://doi.org/10.1046/j.1466-769X.2003.00141.x

[28] Widdershoven, G., Abma, T.A. and Molewijk, B. (2009) Empirical Ethics as Dialogical Practice. Bioethics, 23, 236-248. https://doi.org/10.1111/j.1467-8519.2009.01712.x

[29] Abma, T.A. (2001) Evaluating Palliative Care: Facilitating Reflexive Dialgoues about an Ambiguous Concept. Medicine, Health Care and Philosophy, 4, 261-276. https://doi.org/10.1023/A:1012096917865

[30] Van der Dam, S., Schols, M.G.A.J., Kardol, J.M.T., Molewijk, B., Widdershoven, G. and Abma, T.A. (2013) The Discovery of Deliberation. From Ambiguity to Appreciation through the Learning Process of Doing Moral Case Deliberation in Dutch Elderly Care. Social Science \& Medicine, 83, 125-132.

https://doi.org/10.1016/j.socscimed.2013.01.024

[31] Molewijk, B., van Zadelhoff, E., Lendemeijer, B. and Widdershoven, G. (2008) Implementing Moral Case Deliberation in Dutch Health Care-Improving Moral Competency of Professionals and the Quality of Care. Bioethica Forum, 1, 57-65.

[32] Stolper, M., Molewijk, B. and Widdershoven, G. (2014) Learning by Doing. Training Health Care Professionals to Become Facilitator of Moral Case Deliberation. HEC Forum, 27, 47-59.

[33] Weidema, F., Molewijk, B., Widdershoven, G. and Abma, T.A. (2011) Enacting Ethics: Bottom-Up Involvement in Implementing Moral Case Deliberation. Health Care Analysis, 20, 1-19. https://doi.org/10.1007/s10728-010-0165-5

[34] Rasoal, D., Kihlgren, A., James, I. and Svantesson, M. (2015) What Healthcare Teams Find Ethically Difficult Captured in 70 Moral Case Deliberations. Nursing Ethics, 23, 825-837. https://doi.org/10.1177/0969733015583928

[35] Molewijk, B., Kleinlugtenbelt, D. and Widdershoven, G. (2011) The Role of Emotions in Moral Case Deliberation: Theory, Practice, and Methodology. Bioethics, 25, 383-393. https://doi.org/10.1111/j.1467-8519.2011.01914.x

[36] Molewijk, B., Kleinlugtenbelt, D., Pugh, S.M. and Widdershoven, G. (2011) Emotions and Clinical Ethics Support. A Moral Inquiry into Emotions in Moral Case Deliberation. HEC Forum, 23, 257-268. https://doi.org/10.1007/s10730-011-9162-9

[37] Svantesson, M., Karlsson, J., Boitte, P., Schildman, J., Dauwerse, L., Widdershoven, G., et al. (2014) Outcomes of Moral Case Deliberation-The Development of an Evaluation Instrument for Clinical Ethics Support (the Euro-MCD). BMC Medical Ethics, 15, 30. https://doi.org/10.1186/1472-6939-15-30 
[38] Svantesson, M., Löfmark, R., Thorsén, H., Kallenberg, K. and Ahlström, G. (2008) Learning a Way through Ethical Problems: Swedish Nurses' and Doctors' Experiences from One Model of Ethics Rounds. Journal of Medical Ethics, 34, 399-406. https://doi.org/10.1136/jme.2006.019810

[39] Dauwerse, L., van der Dam, S. and Abma, T.A. (2012) Morality in the Mundane Specific Needs for Ethics Support in Elderly Care. Nursing Ethics, 19, 91-103. https://doi.org/10.1177/0969733011412102

[40] Bousso, R.S., Poles, K. and Rossato, L.M. (2009) Concept Development: New Directions for Research in Thanatology and Nursing. Revista da Escola de Enfermagem da USP, 43, 1331-1336. https://doi.org/10.1590/S0080-62342009000600032

[41] Avant, K.C. (2000) The Wilson Method of Concept Analysis. In: Rodgers, B.L. and Knafl, K.A., Eds., Concept Development in Nursing. Foundations, Techniques, and Applications, 2nd Edition, W.B. Saunders Company, Philadelphia, PA, 55-64.

[42] La Puma, J. and Schiedermayer, D.L. (1991) Ethics Consultation: Skills, Roles, and Training. Annals of Internal Medicine, 114, 155-160. https://doi.org/10.7326/0003-4819-114-2-155

[43] Walker, M.U. (1993) Keeping Moral Space Open: New Images of Ethics Consulting. Hastings Center Report, 23, 33-40. https://doi.org/10.2307/3562818

[44] Orr, R.D., Morton, K.R., de Leon, D.M. and Fals, J.C. (1996) Evaluation of an Ethics Consultation Service: Patient and Family Perspective. American Journal of Medicine, 101, 135-141. https://doi.org/10.1016/S0002-9343(96)80067-2

[45] Kodish, E., Fins, J.J., Braddock, C., Cohn, F., Dubler, N.N., Danis, M., et al. (2013) Quality Attestation for Clinical Ethics Consultants: A Two-Step Model from the American Society for Bioethics and Humanities. Hastings Center Report, 43, 26-36. https://doi.org/10.1002/hast.198

[46] Aulisio, M.P., Arnold, R.M. and Youngner, S.J. (2000) Health Care Ethics Consultation: Nature, Goals, and Competencies: A Position Paper from the Society for Health and Human Values-Society for Bioethics Consultation Task Force on Standards for Bioethics Consultation. Annals of Internal Medicine, 133, 59-69. https://doi.org/10.7326/0003-4819-133-1-200007040-00012

[47] Sporrong, S.K. (2007) Ethical Competence and Moral Distress in the Health Care Sector: A Prospective Evaluation of Ethics Rounds. University of Uppsala, Uppsala.

[48] Hansson, M.G. (2002) Imaginative Ethics-Bringing Ethical Praxis into Sharper Relief. Medicine, Health Care and Philosophy, 5, 33-42. https://doi.org/10.1023/A:1014257603144

[49] Sørlie, V., Lindseth, A., Udén, G. and Norberg, A. (2000) Women Physicians' Narratives about Being in Ethically Difficult Care Situations in Paediatrics. Nursing Ethics, 7, 47-62. https://doi.org/10.1177/096973300000700107

[50] Sørlie, V., Kihlgren, A. and Kihlgren, M. (2004) Meeting Ethical Challenges in Acute Care Work as Narrated by Enrolled Nurses. Nursing Ethics, 11, 179-188. https://doi.org/10.1191/0969733004ne682oa

[51] Tod, A.M., Nicolson, P. and Allmark, P. (2002) Ethical Review of Health Service Research in the UK: Implications for Nursing. Journal of Advanced Nursing, 40, 379-386. https://doi.org/10.1046/j.1365-2648.2002.02385.x

[52] Nordam, A., Torjuul, K. and Sørlie, V. (2005) Ethical Challenges in the Care of Older People and Risk of Being Burned out among Male Nurses. Journal of Clinical Nursing, 14, 1248-1256. https://doi.org/10.1111/j.1365-2702.2005.01230.x

[53] Braunack-Mayer, A.J. (2001) What Makes a Problem an Ethical Problem? An Em- 
pirical Perspective on the Nature of Ethical Problems in General Practice. Journal of Medical Ethics, 27, 98-103. https://doi.org/10.1136/jme.27.2.98

[54] Huynh, T., Alderson, M. and Thompson, M. (2008) Emotional Labour Underlying Caring: An Evolutionary Concept Analysis. Journal of Advanced Nursing, 64, 195-208. https://doi.org/10.1111/j.1365-2648.2008.04780.x 